\title{
Delayed Care Related to COVID-19 in a Nationally Representative Sample of Older Americans
}

KEY WORDS: delayed care; COVID-19; older adults.

J Gen Intern Med 37(5):1337-40

DOI: $10.1007 / \mathrm{s} 11606-022-07417-4$

(C) The Author(s) under exclusive licence to Society of General Internal Medicine 2022

\section{INTRODUCTION}

COVID-19 continues to disrupt US health care, leading to care delays. ${ }^{1}$ Older adults, who have higher levels of functional impairment and comorbidity, may be particularly sensitive to delayed or unmet care. ${ }^{2}$ Analyses of pandemic-related delayed care have not focused on older adults nor examined factors associated with delays, ${ }^{3-6}$ critical information to plan for the future.

\section{METHODS}

The 2020 National Health and Aging Trends Study (NHATS; conducted May-October by phone, response rate $=94.7 \%$ ) is a nationally representative survey of Medicare beneficiaries $\geq 70$ years. A COVID-19 supplement was also fielded from JuneDecember 2020 (by mail, response rate $=82.2 \%$ ). This analysis includes all COVID-19 supplement respondents ( $n=3257)$.

Respondents were asked: "During the COVID-19 outbreak, has there ever been a time when you needed or had planned to see a doctor or other health care provider but put off getting care?" We examined type of and reason for delayed care among those who endorsed delay.

Other respondent characteristics included demographics (sex, age, race/ethnicity), socioeconomic status (marital status, education, Medicaid enrollment, living alone, residential setting), health and functional status, and self-reported comorbidities (heart disease, diabetes, lung disease, stroke, cancer, arthritis, hypertension, dementia, depression, anxiety).

COVID-19-related variables included whether the respondent or others in their household or facility had COVID-19 symptoms, diagnosis, or positive test; COVID-19 was still affecting daily life in the respondent's state; respondents moved to another place or someone else moved in; and having family or friend caregiver during the pandemic.

Received November 11, 2021

Accepted January 13, 2022

Published online January 31, 2022
We used adjusted logistic regression to examine factors associated with delayed care and calculated the mean predicted probability of delayed care for each characteristic, holding all others constant. We used NHATS analytic weights to generate nationally representative estimates. Statistical significance was set a two-tailed $p<.05$. Analyses were performed using STATA, version 15.1.

\section{RESULTS}

Among 3257 respondents $\geq 70$ years (representing 32.7 million older adults), 38.0\% reported delayed care (Fig. 1), including $20.2 \%$ from a dentist; $18.6 \%$, usual doctor; $15.6 \%$, specialist; $15.2 \%$, vision or hearing; $2.8 \%$, surgery; $1.4 \%$, medications; $0.9 \%$, emergency or urgent care; and $6.1 \%$, other (including physical therapy, mental health, or test/lab). The most common reason for delayed care was "the provider cancelled, closed, or suggested rescheduling" (55.5\%), followed by "I decided it could wait" or "a family member did not want me to go" (53.9\%), "I was afraid to go" (28.1\%), or "I could not get an appointment" (10.8\%).

The probability of delayed care was higher among females $(42.1 \%$ vs. $33.0 \%, p<.001$; Table 1$)$ and respondents with at least some college ( $42.8 \%$ vs. $30.6 \%, p<.001$ ); it did not vary by race/ethnicity or Medicaid enrollment. Those with fair or poor general health reported a higher probability of delayed care (e.g., $41.5 \%$ vs. $34.7 \%$ [very good or excellent health], $p=.03$ ); the probability did not vary by functional status.

All COVID-19-related variables were associated with delayed care. The characteristic associated with the highest probability of delayed care was COVID-19 in a respondent's household or facility (56.2\% vs. $37.3 \%, p=.006)$, while those with a family or friend caregiver during the pandemic also had a higher probability of delayed care $(41.3 \%$ vs. $33.9 \%$, $p=.002$ ).

\section{DISCUSSION}

Nearly $40 \%$ of older Americans reported delaying health care during the COVID-19 pandemic, with supply (e.g., provider cancelled) and demand (e.g., respondent decided to delay) factors each reported by over half of respondents with delays. Dental and usual doctor care were most commonly delayed, consistent with findings from nonelderly adults ${ }^{5}$ and estimates from the Center for Medicare and Medicaid Services. ${ }^{6}$ Delays 


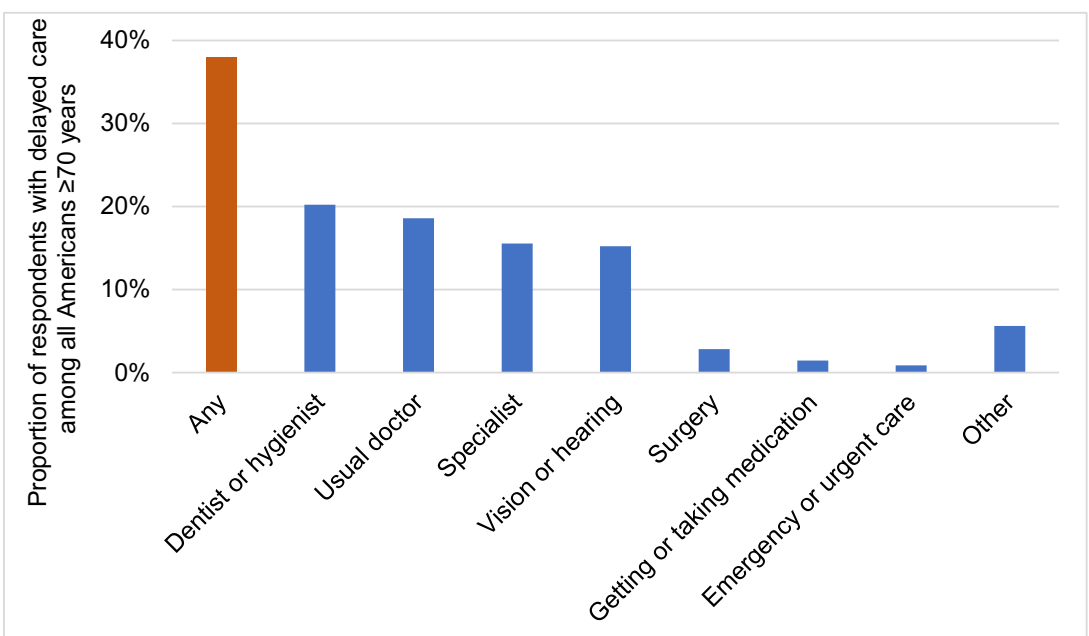

Figure 1. Prevalence of delayed care in a nationally representative sample of Americans aged 70 years or older during the COVID-19 pandemic. Data were weighted using the survey analytic weights. We calculated proportions of respondents who reported any delayed care and each type of care delayed among all Americans aged 70 years or older. Respondents may report more than one type of delayed care (e.g., usual doctor and specialist appointments). "Other" included services such as physical therapy, mental health, or test/lab.

Table 1. Factors Associated with Delayed Care Among Americans Aged 70 Years or Older During the COVID-19 Pandemic

\begin{tabular}{|c|c|c|c|c|c|}
\hline & \multirow{2}{*}{$\begin{array}{l}\text { All respondents, } \\
\%(n=3257)\end{array}$} & \multicolumn{2}{|l|}{ Delayed care } & \multirow[b]{2}{*}{$\begin{array}{l}\text { Adjusted probability, } \\
\%(95 \% \mathrm{CI}) \dagger\end{array}$} & \multirow[b]{2}{*}{$p$-value } \\
\hline & & $\begin{array}{l}\text { Unadjusted proportion, } \\
\% *(n=1187)\end{array}$ & $p$-value & & \\
\hline National estimate & $32,686,642$ & $12,433,906$ & & & \\
\hline \multicolumn{6}{|l|}{ Sex } \\
\hline Male & 44.1 & 34.1 & \multirow[t]{2}{*}{$<.001$} & $33.0(29.8-36.2)$ & [Reference] \\
\hline Female & 55.9 & 41.2 & & $42.1(39.2-45.0)$ & $<.001$ \\
\hline \multicolumn{6}{|l|}{ Age } \\
\hline $70-74$ & 35.4 & 41.8 & \multirow{3}{*}{.03} & $41.0(36.4-45.6)$ & [Reference] \\
\hline $75-84$ & 46.9 & 36.4 & & $36.8(34.2-39.3)$ & .09 \\
\hline $85+$ & 17.7 & 34.8 & & $35.4(30.7-40.1)$ & .09 \\
\hline \multicolumn{6}{|l|}{ Race/ethnicity } \\
\hline Non-Hispanic White & 78.6 & 38.9 & \multirow[t]{4}{*}{.48} & $38.3(35.6-40.9)$ & [Reference] \\
\hline Non-Hispanic Black & 7.8 & 32.1 & & $35.5(30.8-40.1)$ & .30 \\
\hline Hispanic & 7.4 & 35.9 & & $37.7(28.2-47.2)$ & .91 \\
\hline Other & 6.2 & 36.9 & & $38.5(26.1-50.8)$ & .98 \\
\hline \multicolumn{6}{|l|}{ Married } \\
\hline No & 45.8 & 36.9 & \multirow[t]{2}{*}{.43} & $35.9(31.6-40.3)$ & [Reference] \\
\hline Yes & 54.2 & 39.0 & & $39.9(36.3-43.4)$ & .22 \\
\hline \multicolumn{6}{|l|}{ Some college or above } \\
\hline No & 39.2 & 29.9 & \multirow[t]{2}{*}{$<.001$} & $30.6(26.8-34.4)$ & [Reference] \\
\hline Yes & 60.8 & 43.3 & & $42.8(39.6-46.0)$ & $<.001$ \\
\hline \multicolumn{6}{|l|}{ Medicaid enrolled } \\
\hline No & 87.8 & 38.8 & \multirow{2}{*}{.08} & $37.9(35.5-40.4)$ & [Reference] \\
\hline Yes & 12.2 & 32.8 & & $38.8(30.8-46.8)$ & .84 \\
\hline \multicolumn{6}{|l|}{ Living alone } \\
\hline No & 68.4 & 38.1 & \multirow[t]{2}{*}{.99} & $36.8(33.5-40.1)$ & [Reference] \\
\hline \multirow{2}{*}{\multicolumn{6}{|c|}{ Residential setting }} \\
\hline & & & & & \\
\hline Community & 93.6 & 37.9 & \multirow[t]{4}{*}{.12} & $38.4(36.1-40.7)$ & [Reference] \\
\hline Independent living & 3.0 & 50.2 & & $42.8(30.7-54.8)$ & .46 \\
\hline Assisted living & 2.0 & 28.6 & & $24.9(11.0-38.9)$ & .06 \\
\hline Nursing home & 1.4 & 35.4 & & $24.2(8.7-39.7)$ & .07 \\
\hline \multicolumn{6}{|l|}{ General health status } \\
\hline Very good or excellent & 44.6 & 35.8 & \multirow[t]{3}{*}{.21} & $34.7(31.8-37.6)$ & [Reference] \\
\hline Good & 36.3 & 39.9 & & $40.4(36.3-44.6)$ & .03 \\
\hline Fair or poor & 19.1 & 39.8 & & $41.5(36.2-46.9)$ & .03 \\
\hline \multicolumn{6}{|c|}{ Any activities of daily living impairment } \\
\hline No & 64.7 & 37.9 & \multirow[t]{2}{*}{.82} & $38.3(34.9-41.6)$ & [Reference] \\
\hline Yes & 35.3 & 38.4 & & $37.6(33.6-41.6)$ & .82 \\
\hline \multicolumn{6}{|c|}{$\begin{array}{l}\text { Any instrumental activities of daily living } \\
\text { impairment } \S\end{array}$} \\
\hline No & 60.6 & 37.3 & .39 & $37.7(34.7-40.7)$ & [Reference] \\
\hline Yes & 39.4 & 39.2 & & $38.6(34.5-42.7)$ & .73 \\
\hline
\end{tabular}


Table 1.. (continued)

\begin{tabular}{|c|c|c|c|c|c|}
\hline & \multirow{2}{*}{$\begin{array}{l}\text { All respondents, } \\
\%(n=3257)\end{array}$} & \multicolumn{2}{|l|}{ Delayed care } & \multirow[b]{2}{*}{$\begin{array}{l}\text { Adjusted probability, } \\
\%(95 \% \text { CI }) \dagger\end{array}$} & \multirow[b]{2}{*}{$p$-value } \\
\hline & & $\begin{array}{l}\text { Unadjusted proportion, } \\
\%^{*}(n=1187)\end{array}$ & $p$-value & & \\
\hline \multicolumn{6}{|l|}{$\begin{array}{l}\text { COVID-19 symptoms, diagnosis, } \\
\text { or positive test of respondent }\end{array}$} \\
\hline No & 94.4 & 37.4 & .03 & $37.7(35.3-40.2)$ & {$[$ Reference $]$} \\
\hline Yes & 5.6 & 48.8 & & $43.4(33.5-53.3)$ & \\
\hline \multicolumn{6}{|l|}{$\begin{array}{l}\text { COVID-19 symptoms, diagnosis, or positive } \\
\text { test of other persons in the household or facility }\end{array}$} \\
\hline No & 95.8 & 37.2 & $<.001$ & $37.3(34.9-39.6)$ & {$[$ Reference $]$} \\
\hline Yes & 4.2 & 56.9 & & $56.2(43.4-69.1)$ & .006 \\
\hline \multicolumn{6}{|l|}{ COVID-19 still affecting daily life in the state } \\
\hline No & 7.3 & 24.9 & .003 & $28.6(21.0-36.3)$ & [Reference] \\
\hline Yes & 92.7 & 39.1 & & $38.7(36.2-41.3)$ & .02 \\
\hline \multicolumn{6}{|l|}{ Moved to another place during COVID-19 } \\
\hline No & 93.9 & 37.3 & .005 & $37.5(35.1-40.0)$ & [Reference] \\
\hline Yes & 6.1 & 50.0 & & $46.0(38.6-53.4)$ & .03 \\
\hline \multicolumn{6}{|l|}{ Someone else moved in during COVID-19 } \\
\hline No & 93.7 & 37.1 & .003 & $37.3(35.0-39.6)$ & [Reference $]$ \\
\hline Yes & 6.3 & 52.8 & & $49.1(39.1-59.2)$ & .02 \\
\hline \multicolumn{6}{|l|}{ Having family or friend caregiver during } \\
\hline No & 44.2 & 32.5 & $<.001$ & $33.9(30.2-37.5)$ & {$[$ Reference $]$} \\
\hline Yes & 55.8 & 42.4 & & $41.3(38.5-44.1)$ & .002 \\
\hline
\end{tabular}

Data from the 2020 National Health and Aging Trends Study and associated COVID-19 supplement. Data were weighted using the survey analytic weights, which accounted for differential probabilities of selection and non-response; and standard errors were adjusted to account for the complex survey design.

*Unadjusted proportions of delaved care in each stratum of categorical characteristics were reported. Rao-Scott chi-square tests were performed to compare whether unadjusted proportions of delayed care were different for categorical characteristics. For example, overall $44.1 \%$ of respondents were male and $55.9 \%$ were female. Among males, the unadjusted proportion that reported delayed care was $34.1 \%$ versus $41.2 \%$ among females $(p<.001)$. From the logistic regression, the adjusted probability of delayed care was $33.0 \%$ among males versus $42.1 \%$ among females $(p<.001)$.

${ }^{7}$ We performed a logistic regression model to examine factors associated with delayed care among older adults, and then calculated the mean adjusted predicted probability of delayed care for each characteristic while holding constant all other characteristics. We compared whether the predicted probabilities of delayed care were different between strata of the characteristic by calculating the marginal effect of that characteristic using estimates from the logistic regression. The model included all characteristics included in the table rows, in addition to self-reported clinical conditions (heart disease, diabetes, lung disease, stroke, cancer, arthritis, hypertension, dementia, depression, anxiety). The adjusted probability of delayed care did not differ across clinical conditions except that respondents with anxiety were more likely to report delayed care $(45.0 \%$ vs. $37.4 \%$, $p=.04)$

${ }^{7}$ Activities of daily living included getting out of bed, getting around one's home or building, bathing, dressing, eating, and toileting

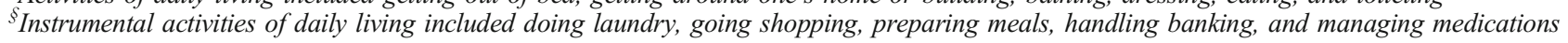

of such services highlight the contribution of both demand(e.g., respondents perceive routine services as delayable) and supply-related (e.g., state orders to postpone elective care, potentially including dental and usual doctor visits) factors.

These findings also underscore the impact of COVID-19related household disruptions, with household COVID increasing the likelihood of delayed care by the largest margin of all characteristics. Other pandemic household changes (e.g., respondent moving or someone moving in with the respondent) were also associated with delay. Finally, caregiving dyads appeared to be at particular risk: While a prior analysis demonstrated unpaid caregivers delayed their own care due to COVID, ${ }^{4}$ respondents in this analysis with family or friend caregivers also reported delayed care. In other words, during this pandemic, both members of caregiving dyads have experienced delayed health care.

Acknowledgements: National Health and Aging Trends Study is sponsored by National Institute on Aging Grant NIA UO1AG032947 through a cooperative agreement with the Johns Hopkins Bloomberg School of Public Health.
Lianlian Lei, $P h D^{1}$

Donovan T. Maust, MD, MS ${ }^{1,2,3}$

${ }^{1}$ Department of Psychiatry, University of Michigan, Rachel Upjohn Building, 4250, Road Ann Arbor, Plymouth, MI 48109, USA

${ }^{2}$ Institute for Healthcare Policy and Innovation, University of Michigan,

Ann Arbor, MI, USA

${ }^{3}$ Center for Clinical Management Research, VA Ann Arbor Healthcare System,

Ann Arbor, MI, USA

Corresponding Author: Lianlian Lei, PhD; Department of Psychiatry, University of Michigan, Rachel Upjohn Building, 4250, Road Ann Arbor, Plymouth, MI 48109, USA (e-mail: leilian@med.umich.edu).

Funding Funding for this work was provided by the R01 AG056407 (Lei and Maust).

\section{Declarations:}

This study was approved by the Institutional Review Board of the University of Michigan Medical School. 
Conflict of interest: The authors declare that they do not have a conflict of interest.

\section{REFERENCES}

1. Findling MG, Blendon RJ, Benson JM. Delayed care with harmful health consequences-Reported experiences from national surveys during coronavirus disease 2019. JAMA Health Forum. 2020;1(12):e201463. [PMID: 33298131]. doi: https://doi.org/10.1001/jamahealthforum.2020.1463.

2. Grossman M. On the Concept of Health Capital and the Demand for Health. J Polit Econ. 1972;80(2):223-55.

3. Callison K, Ward J. Associations Between Individual Demographic Characteristics And Involuntary Health Care Delays As A Result Of COVID-19. Health Aff. 2021;40(5):837-43. [PMID: 33881908]. doi: https://doi.org/10. $1377 /$ hlthaff.2021.00101.

4. Czeisler MÉ, Marynak K, Clarke KE, et al. Delay or avoidance of medical care because of COVID-19-related concerns-United States, June 2020.
Morb Mortal Wkly Rep. 2020;69(36):1250. [PMID: 32915166]. doi: https:// doi.org/10.15585/mmwr.mm6936a4.

5. Gonzalez D, Karpman M, Kenney GM, Zuckerman S. Delayed and Forgone Health Care for Nonelderly Adults during the COVID-19 Pandemic. Washington, DC: Urban Institute, February 2021 Available from: https:// www.urban.org/sites/default/files/publication/103651/delayed-and-forgone-health-care-for-nonelderly-adults-during-the-covid-19-pandemic. pdf. .

6. Centers for Medicare \& Medicaid Services. COVID-19 Experiences Among the Medicare Population. October 2020. Available from: https://www.cms. gov/files/document/medicare-current-beneficiary-survey-summer-2020covid-19-data-snapshot.pdf. Accessed November 2, 2021.

Publisher's Note: Springer Nature remains neutral with regard to jurisdictional claims in published maps and institutional affiliations. 